\title{
Physical activity, physical fitness, blood pressure, and fibrinogen in the Northern Ireland health and activity survey
}

\author{
D MacAuley, E E McCrum, G Stott, A E Evans, B McRoberts, C A G Boreham, \\ K Sweeney, T R Trinick
}

Abstract

Study objective - To investigate the relationship between physical activity, physical fitness, blood pressure, and fibrinogen.

Design - This was a cross sectional population study using a two stage probability sample.

Setting - Northern Ireland.

Participants - A sample of 1600 subjects aged 16-74 years from the population of Northern Ireland.

Main outcome measures - Physical activity profile from computer assisted interview using the Allied Dunbar national fitness survey scales. Physical fitness using estimation of $\mathrm{VO}_{2}$ max by extrapolation from submaximal oxygen uptake while walking on a motor driven treadmill. Systolic and diastolic blood pressure measured with a Hawksley random zero sphygmomanometer. Measurement of fibrinogen using the Clauss method.

Main results - There were significant relationships between both current and past activity and blood pressure. These were of a magnitude that would have been clinically significant, but for the fact that, with the exception of the relationship between habitual activity and diastolic pressure $(p=0.03)$ and past activity and systolic pressure $(p=0.03)$ in men, they were not sustained after adjustment for the effect of age using analysis of variance. After adjustment for other potentially confounding factors using multiple regression, there was an inverse relationship between systolic blood pressure and past activity in men, so that those with a lifetime of participation compared with a lifetime of inactivity had a lower systolic blood pressure of $6 \mathrm{mmHg}(p<0 \cdot 05)$. There was a highly significant $(p<0.001)$ inverse association between both systolic and diastolic blood pressure and physical fitness $\left(V_{2} O_{2}\right.$ max) which was not sustained after adjustment for possible confounding factors. There were relationships between fibrinogen and highest recorded activity $(p<0 \cdot 001)$, habitual activity $(p<0 \cdot 01)$, and past activity $(p<0.01)$ in men but no significant relationship in women. The relationship between fibrinogen and activity was no longer sustained after adjustment for possible confounding factors. There was a highly significant $(\mathbf{p}<0 \cdot 001)$ inverse relationship with physical fitness using $\mathrm{VO}_{2}$ max. This relationship was sustained after adjustment for possible confounding factors in both men $(p<0.05)$ and women $(\mathrm{p}<0 \cdot 001)$.

Conclusions - There was a relationship between physical activity, physical fitness, and blood pressure but the relationship was greatly influenced by age. A reduction of $6 \mathrm{mmHg}$ in systolic blood pressure associated with past activity is of clinical significance and supports the hypothesis that physical activity is of benefit in reducing cardiovascular risk. There was a lower level of fibrinogen in those who were most active but this relationship was not significant after adjustment for possible confounding factors. There was also a lower level of fibrinogen those who were most fit $\left(\mathrm{VO}_{2}\right.$ max) and this relationship persisted even after adjustment for possible confounding factors.

( $(\mathcal{E}$ Epidemiol Community Health 1996;50:258-263)

There is considerable evidence supporting the beneficial effect of physical activity and physical fitness on cardiovascular mortality and the effect on risk factors, such as hypertension and plasma fibrinogen, may be one possible mechanism. Epidemiological studies have shown a reduced risk of developing hypertension in physically active persons ${ }^{12}$ and a meta-analysis of 25 longitudinal studies ${ }^{3}$ confirmed the benefits of aerobic exercise in lowering raised systolic and diastolic blood pressures. There is an inverse relationship between vigorous sports participation and hypertension $^{4}$ and the relationship between physical activity and blood pressure has been shown to be independent of age, body mass index (BMI), and fasting plasma insulin levels. Blair et $a l^{6}$ found that those with low levels of physical fitness have a relative risk of 1.52 for the development of hypertension when compared with those who are very fit. Intervention including exercise, was shown to reduce the risk of developing hypertension ${ }^{7}$ in a controlled trial of those with high-normal blood pressure at baseline, and has also been shown to lowe systolic blood pressure by $11 \mathrm{mmHg}$ and diastolic blood pressure by $8 \mathrm{mmHg}$ in those with mild to moderate hypertension. ${ }^{3}$ In general, there has been a linear relationship between activity and blood pressure, but the multiple 
risk factor intervention trial study ${ }^{8}$ and British regional heart study" suggested a " $\mathrm{J}$ " shaped curve.

There is also interest in the relationship with between physical activity, physical fitness, and fibrinogen. Plasma fibrinogen is a well documented risk factor for cardiovascular disease, ${ }^{1011}$ which is independent of hypertension. Fibrinogen has a role in the clotting mechanism and thus plays an important part in thrombosis. There is evidence from cross sectional ${ }^{12-16}$ and longitudinal ${ }^{17}$ studies of reduced fibrinogen in those undertaking physical activity.

This study offers the opportunity to explore the relationship between exercise, fitness, and these two important risk factors. Its aim was to examine the relationship between physical activity, physical fitness, blood pressure, and fibrinogen in a cross sectional population survey of physical activity, other lifestyle parameters, and cardiovascular risk factors in Northern Ireland. ${ }^{18}$ The particular benefits of this study are the detailed measure of physical activity and the direct measurement of physical fitness using oxygen uptake, and the study is particularly pertinent in a population known for its high level of cardiovascular disease. ${ }^{19}$

\section{Methods}

The Northern Ireland health and activity survey (NIHAS), which was designed to yield a representative sample of adults aged 16 years or over in Northern Ireland, employed two stage probability sampling. The first stage was a sample of 1600 addresses taken from the Northern Ireland rating and valuation lists, stratified by region to ensure proportional sampling across the province. The second stage was carried out by the interviewers so that one person was selected in each household using a Kish grid random selection procedure ${ }^{20}$ to avoid any chance of self selection by members of the household or bias on the part of the interviewer.

A sample drawn using the Kish grid sampling method is influenced by the numbers in each household, thus the sample was weighted to take account of household size and the appropriate adjustment was made to the method of calculating the standard errors.

The fieldwork, which was completed between February and November 1992, comprised three parts - a computer assisted interview, a physical appraisal, and fasting blood sample determination. The questionnaire was similar (with some modifications relevant to Northern Ireland which did not affect the meaning of the questions; for example to allow for the different measures of alcohol), and the physical appraisal was identical to that used in the Allied Dunbar national fitness survey (ADNFS) ${ }^{21}$ The questionnaire was carried out using computer-assisted interviewing and a copy of the questionnaire on disk may be obtained from the Sports Council for Northern Ireland. Those defined as hypertensive included both those whose blood pressure was $160 / 95$ and those who were taking medication for high blood pressure.
Physical activity was classified under three headings:

- The highest level of activity in the four weeks before the interview (none, light, moderate, vigorous).

- The frequency and intensity of bursts of physical activity lasting twenty minutes in the four weeks before the interview which is a more accurate reflection of habitual activity (6 categories: level 0-level 5).

- The years of regular participation in sport and exercise since age 14 years in five categories giving the proportion of life that the person had been active $(0,<0 \cdot 25,0 \cdot 25-0.49$, $0 \cdot 50-0.74,0.75 \%$ ).

The physical appraisal was performed in a specially designed mobile laboratory at 14 hospital sites throughout the province. Height was measured using a Holtain stadiometer and body weight was measured to the nearest $0 \cdot 1 \mathrm{~kg}$ using a Phillips Electronic scale (HP 5320). Body mass index was used as an index of obesity. Blood pressure was measured with a Hawksley random zero sphygmomanometer. Blood pressure measurements were taken after the height and weight measurements, but before any physical activity. Three readings were taken at one minute intervals after the subject had been sitting resting for 5 minutes. Blood pressure was measured on the left arm using an appropriate sized cuff and diastolic pressure determined using the Korotkoff method. ${ }^{5}$ The physical appraisal team $(n=4)$ had regular quality assurance appraisals for technique and interobserver comparability, and the sphygmomanometer was subsequently tested for accuracy.

Aerobic fitness was assessed by oxygen uptake while walking on a treadmill. Maximum oxygen uptake $\left(\mathrm{VO}_{2}\right.$ max) was calculated by extrapolation from performance at up to $85 \%$ of predicted maximum heart rate. Oxygen uptake, in litres per minute corrected for body weight, and heart rate were recorded on the treadmill three times each minute. A least squares regression line was drawn through each respondent's set of data points. Regression by the least squares method calculates a straight line through each set of data points. Estimation of $\mathrm{VO}_{2}$ max using this method may be limited by the assumption that each individual has the same maximum heart rate related to age. In addition, the number of data points varied, with some fitter individuals proceeding through the whole 16 minute protocol and others only managing a few minutes before their heart rate rose above $85 \%$ of their predicted maximum for age ( 220 beats per minute - age).

The more demanding protocol began at a treadmill speed of $3 \mathrm{~km}$ per hour achieving a mid range speed of $5 \mathrm{~km}$ per hour from the 5 th minute to the 14th minute. Gradient changes were made every minute from the 6 th minute to the 13th minute up to 20 degrees. For fitter subjects, two further speed increments were included to take the subject to target heart rate. The less demanding protocol was at a constant speed of $3 \mathrm{~km}$ per hour with an increase in the gradient. These test protocols were identical to those used in the ADNFS. ${ }^{21}$ 
Table 1 Response to components of Northern Ireland health and activity survey

\begin{tabular}{lrc}
\hline & No & $\%$ \\
\hline Valid addresses & 1456 & 100 \\
Total interviewed, all ages & 1020 & $70 \cdot 1$ \\
Attended centre for appraisal & 567 & $38 \cdot 6$ \\
Analysable treadmill data & 481 & $33 \cdot 0$ \\
Blood tests & 633 & $43 \cdot 5$ \\
\hline
\end{tabular}

A fasting blood sample $(30 \mathrm{ml})$ was taken on a morning during the week preceding the physical appraisal or not less than two days after the physical appraisal at the respondent's home, place of work, or at the physical appraisal laboratory. Participants had been given verbal instructions and an explanatory letter requesting that they fast from all food and alcohol for 12 hours before the blood test. Samples were centrifuged at $3000 \mathrm{rpm}$ at room temperature, separated, and analysed on the same day. The laboratory is accredited with Clinical Pathology Accreditation UK Ltd. External and internal quality control procedures were used to monitor the quality of the laboratory analyses. Measurement of fibrinogen was by the manual Clauss method ${ }^{22}$ (Boehringer Mannheim) using control plasma from Immuno Ltd (Sevenoaks, Kent TN14 5HB, UK).

Data were analysed using SPSS on the Microvax 3100 computer at the Department of Epidemiology and Public Health, The Queen's University of Belfast. Analysis of variance was used for comparison of mean blood pressure and mean fibrinogen between activity groups, and two way analysis of variance was used to adjust for age. The association between blood pressure and fibrinogen with activity (or fitness) was examined using multiple regression to adjust for the influence of age, body mass index, alcohol intake (none, 1-9, 10 + units per week), smoking (none, cigars/pipe or $<10$ cigarettes, $10+$ cigarettes per day), education (tertiary, secondary, primary), social class (non-manual,

Table 2 Systolic blood pressure $(\mathrm{mmHg}):$ men and women

\begin{tabular}{llcccccc}
\hline \multicolumn{7}{c}{ Age groups $(y)$} & \multicolumn{1}{l}{} \\
\cline { 2 - 8 } & All & $16-24$ & $25-34$ & $35-44$ & $45-54$ & $55-64$ & $65-74$ \\
\hline Men & & & & & & & \\
No & 305 & 57 & 69 & 62 & 61 & 27 & 29 \\
Mean & 122 & 115 & 120 & 117 & 120 & 133 & 142 \\
(SD) & $(16)$ & $(10)$ & $(13)$ & $(13)$ & $(15)$ & $(19)$ & $(18)$ \\
(SEM) & $(1 \cdot 0)$ & $(1 \cdot 5)$ & $(1 \cdot 8)$ & $(1 \cdot 8)$ & $(2 \cdot 2)$ & $(4 \cdot 1)$ & $(3 \cdot 9)$ \\
Women & & & & & & & \\
No & 299 & 59 & 60 & 58 & 56 & 34 & 31 \\
Mean & 117 & 104 & 106 & 112 & 124 & 135 & 135 \\
(SD) & $(20)$ & $(10)$ & $(12)$ & $(14)$ & $(16)$ & $(26)$ & $(22)$ \\
(SEM) & $(1 \cdot 3)$ & $(1 \cdot 4)$ & $(1 \cdot 8)$ & $(2 \cdot 1)$ & $(2 \cdot 5)$ & $(5 \cdot 0)$ & $(4 \cdot 5)$ \\
\hline
\end{tabular}

Table 3 Diastolic blood pressure $(\mathrm{mmHg})$ : men and women

\begin{tabular}{llllllll}
\hline \multicolumn{7}{c}{ Age groups $(y)$} \\
\cline { 2 - 8 } & All & $16-24$ & $25-34$ & $35-44$ & $45-54$ & $55-64$ & $65-74$ \\
\hline Men & & & & & & & \\
No & 305 & 57 & 69 & 62 & 61 & 27 & 29 \\
Mean & 76 & 69 & 75 & 75 & 79 & 80 & 79 \\
(SD) & $(11)$ & $(8)$ & $(10)$ & $(11)$ & $(9)$ & $(15)$ & $(13)$ \\
(SEM) & $(0 \cdot 7)$ & $(1 \cdot 2)$ & $(1 \cdot 4)$ & $(1 \cdot 6)$ & $(1 \cdot 3)$ & $(3 \cdot 3)$ & $(2 \cdot 6)$ \\
Women & & & & & & & \\
No & 299 & 59 & 60 & 58 & 56 & 34 & 31 \\
Mean & 71 & 66 & 65 & 71 & 78 & 78 & 75 \\
(SD) & $(11)$ & $(7)$ & $(8)$ & $(8)$ & $(11)$ & $(11)$ & $(10)$ \\
(SEM) & $(0 \cdot 7)$ & $(1 \cdot 0)$ & $(1 \cdot 2)$ & $(1 \cdot 2)$ & $(1 \cdot 7)$ & $(2 \cdot 1)$ & $(2 \cdot 0)$ \\
\hline
\end{tabular}

manual), and diet (good, bad; based on consumption of dietary fat and fibre by dietary questionnaire). The survey was approved by the Research Ethical Committee of the Faculty of Medicine, The Queens University of Belfast.

\section{Results}

There were 1456 effective addresses - 145 (10\%) non-contacts, $285(20 \%)$ refused interview, 1020 achieved interviews (70\%), and 6 missing questionnaires (table 1). The weighted sample (M 474: F 546) was comparable to the population distribution of the 1991 Northern Ireland census in relation to sex and age and those who attended the physical appraisal were representative of those who completed the questionnaire in respect of age, height, weight, physical activity, health, and obesity, although they were more likely to be male and nonsmokers $(p<0.05)$. The figures given in the tables are for the weighted sample.

Mean systolic and diastolic blood pressures are shown in tables 2 and 3. There was an increase in the mean systolic blood pressure with increasing age in both men $(\mathrm{p}<0.001)$ and in women $(p<0.001)$. Overall, $6 \%$ of men and women were hypertensive using criteria suggested in 1992 by the European Atherosclerosis Society, ${ }^{23}$ and using WHO criteria, ${ }^{24}$ the overall proportions of men and women who were hypertensive were $6 \%$ and $5 \%$ respectively.

The relationships between physical activity and both systolic and diastolic blood pressures were confounded by age, and after adjustment for age only the relationships between habitual activity and diastolic pressure among men $(\mathrm{p}=$ 0.03 ) and past activity and systolic blood pressure in men were sustained $(p=0.03)$.

The relationships between habitual activity, highest recorded activity, past participation, $\mathrm{VO}_{2}$ max, and blood pressure were examined using multiple regression (table 4). There was a highly significant positive relationship in both men and women between systolic and diastolic blood pressure and age $(\mathrm{p}<0.001)$ and $\mathrm{BMI}$ $(p<0.001)$. There was an inverse relationship with $\mathrm{VO}_{2} \max (\mathrm{p}<0.001)$, but this was not significant after adjustment for possible confounding factors (age, BMI, smoking, alcohol intake, education, social class, and diet).

There was also a relationship between blood pressure and habitual activity in men, with a lower mean systolic blood pressure of $10 \mathrm{mmHg}(\mathrm{p}<0.01)$ and a lower diastolic blood pressure of $5 \mathrm{mmHg}(\mathrm{p}<0.05)$ for level $5 \mathrm{com}$ pared with level 0 . In women there was a lower systolic blood pressure of $9 \mathrm{mmHg}(p<0.05)$ and a lower diastolic blood pressure of $5 \mathrm{mmHg}$ $(p<0.01)$ between levels 3,4 and level 0 ; combining levels 4,5 because of small cell sizes resulted in a lower systolic blood pressure of $9 \mathrm{mmHg}(\mathrm{p}<0.05)$ and diastolic blood pressure of $7 \mathrm{mmHg}(\mathrm{p}<0.01)$ for levels 4,5 compared with level 0 .

Using the highest recorded activity, the systolic and diastolic blood pressures in men were lower by $15 \mathrm{mmHg}(\mathrm{p}<0.01)$ and $8 \mathrm{mmHg}$ $(p<0.05)$ respectively and those in women by $22 \mathrm{mmHg}(\mathrm{p}<0.01)$ and $11 \mathrm{mmHg}(\mathrm{p}<0.01)$ 
Table 4 Multiple regression analysis of systolic and diastolic blood pressure (BP) and their determinants: men and women (coefficient (SEM))

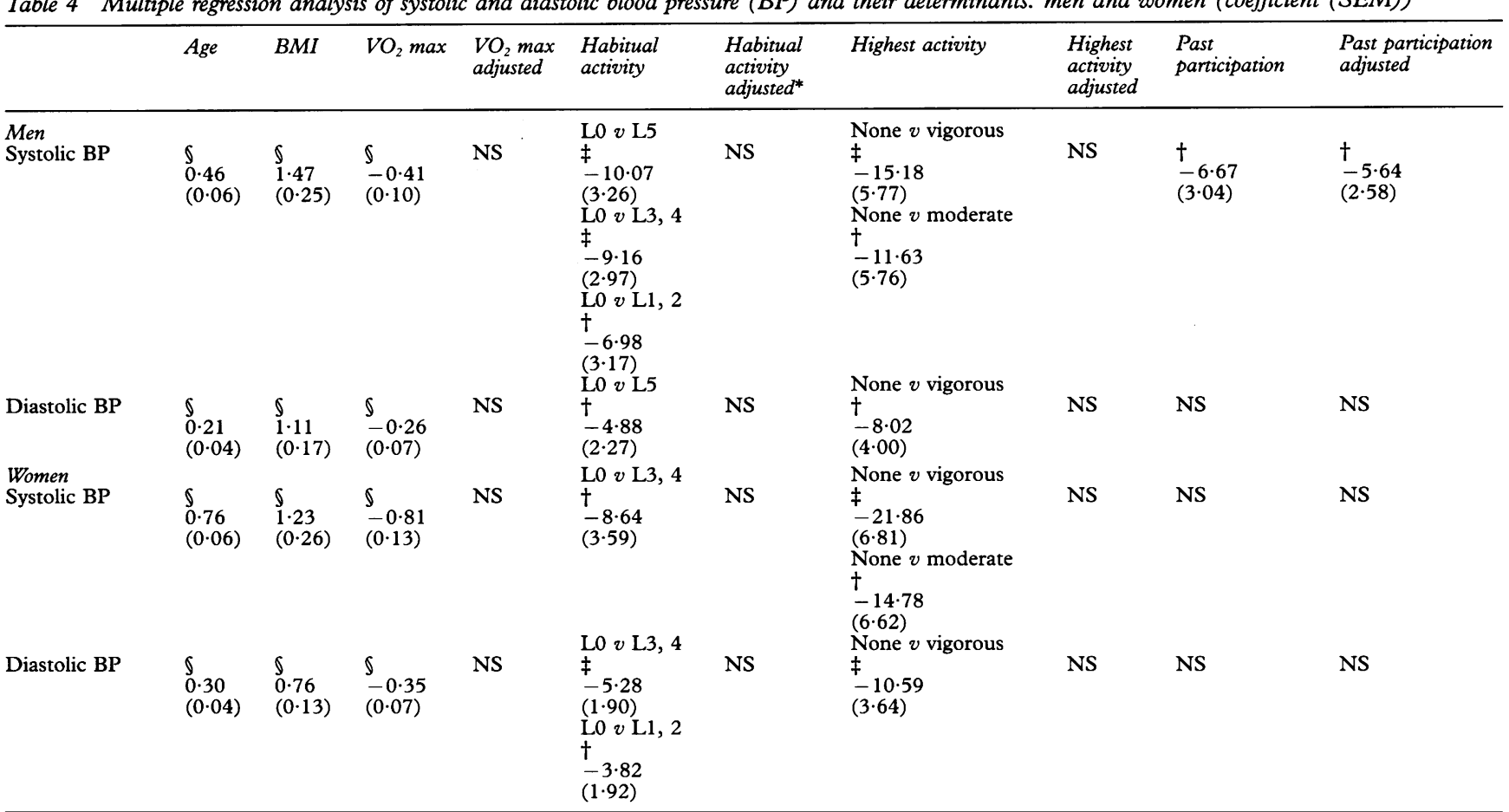

* Adjusted $=$ adjusted for possible confounding variables; $\uparrow \mathrm{p}<0.05 ; \ddagger \mathrm{p}<0.01 ; \S \mathrm{p}<0.001$.

respectively for those undertaking vigorous activity compared with no activity. These associations were confirmed when the none/light categories were combined due to small cell sizes.

There were also lower mean systolic pressures of $7 \mathrm{mmHg}(\mathrm{p}<0.05)$ before and $6 \mathrm{mmHg}$ $(p<0.05)$ after adjustment for possible confounders between men with a lifetime of participation compared with those who had been inactive all their life.

There was a highly significant increase in fibrinogen with age $(p<0 \cdot 001)$. Fibrinogen was positively associated with BMI $(p<0.001)$ in both men and women. There was a relationship between cigarette smoking status in men before $(p=0.03)$ and after $(p=0.004)$ adjustment for age, but there was no relationship in women. In men there was a significantly lower fibrinogen with habitual activity $(p=0.02)$, highest recorded activity $(p<0.001)$, and past activity $(p=0.001)$. After adjustment for possible confounding factors, these differences were no longer statistically significant. There was no significant association between fibrinogen and habitual activity, highest recorded activity, or past activity in women (table 5A, $\mathrm{B}, \mathrm{C})$.

There was a highly significant $(p<0.001)$ inverse association between fibrinogen and fitness as measured by $\mathrm{VO}_{2}$ max, in both men and women. In men the relationship was such that an increase in $\mathrm{VO}_{2} \max$ of $1 \mathrm{ml} / \mathrm{kg} / \mathrm{min}$ was associated with a decrement of $0.03 \mathrm{~g} / 1$ in fibrinogen. This inverse association persisted after adjustment for possible confounders, with an increase of $1 \mathrm{ml} / \mathrm{kg} / \mathrm{min}$ in $\mathrm{VO}_{2} \max$ suggesting a decrease in fibrinogen of $0.01 \mathrm{~g} / 1$ $(\mathrm{p}<0.05)$. In women an increase in $\mathrm{VO}_{2} \mathrm{max}$ of $1 \mathrm{ml} / \mathrm{kg} / \mathrm{min}$ was associated with a decrement of $0.02 \mathrm{~g} / 1$ in fibrinogen even after adjustment for possible confounders $(p<0.001)$.

\section{Discussion}

The age related increase of $27 \mathrm{mmHg}$ in systolic blood pressure among men in Northern Ireland was greater than that found in the corresponding survey in England ${ }^{25}$ (the ADNFS; $16 \mathrm{mmHg}$ ), while the increase of $31 \mathrm{mmHg}$ among women was comparable (ADNFS; $32 \mathrm{mmHg}$ ). The rise in diastolic blood pressure of $10 \mathrm{mmHg}$ from age 16-74 years among men was similar (ADNFS; $8 \mathrm{mmHg}$ ) although the rise of $9 \mathrm{mmHg}$ among women was less (ADNFS; $15 \mathrm{mmHg}$ ).

While there were reductions in systolic and diastolic blood pressures with increasing physical activity of a magnitude that would be of clinical significance, the association was no longer significant, with the exception of the reduction in systolic blood pressure with past activity in men, when multiple regression was used to adjust for age, BMI, smoking, alcohol intake, education, social class, and diet. This supports the suggestion by Gordon et $a l^{2}$ that much of the relationship between blood pressure and physical activity stems from confounding factors other than physical activity alone. They have pointed out the wide variability in outcome between the studies and suggested that the blood pressure lowering effects may be at least partly dependent on gender, BMI, intensity of exercise, duration of training, and initial blood pressure. A reduction of $6 \mathrm{mmHg}$ in systolic blood pressure with past activity is, however, of clinical significance and supports the suggestion that lifelong habitual physical activity is of benefit in reducing cardiovascular risk. 
Table 5 Fibrinogen related to highest recorded activity, to habitual activity and to past participation (proportion of life active): men and women

(A) Fibrinogen related to highest recorded activity

\begin{tabular}{|c|c|c|c|c|c|c|}
\hline Highest & None & Light & Moderate & Vigorous & $p$ & Adjusted for age \\
\hline $\begin{array}{l}\text { Men } \\
\text { No } \\
\text { Mean } \\
(95 \% \mathrm{CI})\end{array}$ & $\begin{array}{l}9 \\
3 \cdot 55 \\
(2 \cdot 81,4 \cdot 29)\end{array}$ & $\begin{array}{l}18 \\
3 \cdot 62 \\
(3 \cdot 16,4 \cdot 07)\end{array}$ & $\begin{array}{l}129 \\
3 \cdot 14 \\
(2 \cdot 99,3 \cdot 29)\end{array}$ & $\begin{array}{l}110 \\
2 \cdot 84 \\
(2 \cdot 71,2 \cdot 97)\end{array}$ & $<0.001$ & $0 \cdot 49$ \\
\hline $\begin{array}{l}\text { Women } \\
\text { No } \\
\text { Mean } \\
(95 \% \text { CI) }\end{array}$ & $\begin{array}{l}15 \\
3 \cdot 29 \\
(2 \cdot 64,3 \cdot 94)\end{array}$ & $\begin{array}{l}16 \\
3 \cdot 60 \\
(3 \cdot 17,4 \cdot 02)\end{array}$ & $\begin{array}{l}179 \\
3 \cdot 34 \\
(3 \cdot 21,3 \cdot 48)\end{array}$ & $\begin{array}{l}81 \\
3 \cdot 20 \\
(3 \cdot 01,3 \cdot 40)\end{array}$ & $0 \cdot 41$ & $0 \cdot 70$ \\
\hline
\end{tabular}

(B) Fibrinogen related to habitual activity

\begin{tabular}{|c|c|c|c|c|c|c|c|c|}
\hline Habitual & Level 0 & Level 1 & Level 2 & Level 3 & Level 4 & Level 5 & $p$ & Adjusted for age \\
\hline $\begin{array}{l}\text { Men } \\
\text { No } \\
\text { Mean } \\
(95 \% \mathrm{CI}) \\
\text { Women }\end{array}$ & $\begin{array}{l}47 \\
3 \cdot 39 \\
(3 \cdot 12,3 \cdot 66)\end{array}$ & $\begin{array}{l}47 \\
3 \cdot 14 \\
(2 \cdot 91,3 \cdot 38)\end{array}$ & $\begin{array}{l}20 \\
3 \cdot 11 \\
(2 \cdot 62,3 \cdot 61)\end{array}$ & $\begin{array}{l}71 \\
3 \cdot 03 \\
(2 \cdot 84,(3 \cdot 22)\end{array}$ & $\begin{array}{l}24 \\
2 \cdot 78 \\
(2 \cdot 60,2 \cdot 96)\end{array}$ & $\begin{array}{l}56 \\
2 \cdot 87 \\
(2 \cdot 67,3 \cdot 08)\end{array}$ & $0 \cdot 02$ & $0 \cdot 87$ \\
\hline $\begin{array}{l}\text { Women } \\
\text { No } \\
\text { Mean } \\
(95 \% \mathrm{CI})\end{array}$ & $\begin{array}{l}60 \\
3 \cdot 47 \\
(3 \cdot 22,3 \cdot 73)\end{array}$ & $\begin{array}{l}50 \\
3 \cdot 26 \\
(2 \cdot 96,3 \cdot 57)\end{array}$ & $\begin{array}{l}49 \\
3 \cdot 36 \\
(3 \cdot 09,3 \cdot 63)\end{array}$ & $\begin{array}{l}86 \\
3 \cdot 24 \\
(3 \cdot 09,(3 \cdot 39)\end{array}$ & $\begin{array}{l}25 \\
3 \cdot 00 \\
(2 \cdot 78,3 \cdot 22)\end{array}$ & $\begin{array}{l}20 \\
3 \cdot 55 \\
(2 \cdot 95,4 \cdot 15)\end{array}$ & $0 \cdot 22$ & $0 \cdot 44$ \\
\hline
\end{tabular}

(C) Fibrinogen related to past participation (proportion of life active)

\begin{tabular}{|c|c|c|c|c|c|c|c|}
\hline Past & 0 & $<0 \cdot 25$ & $0.25-0.49$ & $0.50-0.74$ & $0.75+$ & $p$ & Adjusted for age \\
\hline $\begin{array}{l}\text { Men } \\
\text { No } \\
\text { Mean } \\
(95 \% \text { CI })\end{array}$ & $\begin{array}{l}16 \\
3 \cdot 55 \\
(3 \cdot 13,3 \cdot 97)\end{array}$ & $\begin{array}{l}22 \\
3 \cdot 23 \\
(2 \cdot 91,3 \cdot 54)\end{array}$ & $\begin{array}{l}35 \\
3 \cdot 29 \\
(2 \cdot 92,3 \cdot 67)\end{array}$ & $\begin{array}{l}24 \\
3 \cdot 36 \\
(2 \cdot 96,3 \cdot 76)\end{array}$ & $\begin{array}{l}169 \\
2 \cdot 91 \\
(2 \cdot 80,3 \cdot 02)\end{array}$ & 0.001 & 0.02 \\
\hline $\begin{array}{l}\text { Women } \\
\text { No } \\
\text { Mean } \\
(95 \% \text { CI })\end{array}$ & $\begin{array}{l}33 \\
3 \cdot 04 \\
(2 \cdot 69,3 \cdot 38)\end{array}$ & $\begin{array}{l}27 \\
3 \cdot 32 \\
(2 \cdot 96,3 \cdot 68)\end{array}$ & $\begin{array}{l}38 \\
3 \cdot 56 \\
(3 \cdot 23,3 \cdot 90)\end{array}$ & $\begin{array}{l}35 \\
3 \cdot 18 \\
(2 \cdot 81,3 \cdot 54)\end{array}$ & $\begin{array}{l}157 \\
3 \cdot 34 \\
(3 \cdot 21,3 \cdot 47)\end{array}$ & $0 \cdot 15$ & $0 \cdot 19$ \\
\hline
\end{tabular}

The highly significant inverse association between blood pressure and aerobic fitness, as measured by $\mathrm{VO}_{2} \max$, was also eliminated after multiple regression was used to adjust for the confounding factors listed above.

There was a relationship between physical activity and fibrinogen, as would have been expected from previous studies, and the margin of difference was both statistically and clinically significant. It is well known that age and smoking habit confound the relationship with fibrinogen, and the relationship between fibrinogen and activity was no longer sustained after adjustment for these confounders. This is in keeping with the work of Lee et al, ${ }^{15}$ who suggested that the relationship between activity and fibrinogen could largely be explained by smoking, while Connelly et $a l^{26}$ found that those who were vigorously active had lower fibrinogen levels, even after adjustment for age, smoking, alcohol, BMI, and occupation.

Ernst $^{17}$ reviewed the relationship between physical activity and fibrinogen levels in longitudinal studies and found evidence of a reduction of about $0.4 \mathrm{~g} / 1$ with physical activity which is important when we consider that the Northwick Park heart study ${ }^{27}$ found that a $0 \cdot 1 \mathrm{~g} / 1$ difference in fibrinogen corresponded to a reduction of $15 \%$ in the risk of coronary heart disease.

While the relationship with physical activity was no longer sustained after adjustment for age and smoking, the relationship between fibrinogen and physical fitness was sustained. Lakka et $a{ }^{28}$ suggested that the plasma reducing effect of conditioning physical activity was largely due to increased fitness. Moller and Kristensen ${ }^{29}$ suggested that one possible pathway may be physical activity $\rightarrow$ physical fitness $\rightarrow$ fibrinogen, but one would have expected that in this model the relationship with physical activity would have been sustained.

Physical activity and physical fitness are not the same, although physical fitness is often wrongly used as a surrogate measure of activity. Physical activity is defined as bodily movement produced by skeletal muscles that results in energy expenditure while physical fitness is a set of physiological attributes that people have or achieve that relate to the ability to perform physical activity. The physical fitness component that has been most frequently studied in relation to health is aerobic power. Physical fitness has a large genetic component, although it is modified by activity, and it is often difficult to unravel the relationships between physical activity which is voluntary and physical fitness which is essentially constitutional. The relationship between fibrinogen, physical activity, and physical fitness may suggest a constitutional effect.

A particular strength of this study is the detailed measure of physical activity. This included physical activity at work and during leisure time in a detailed aggregate based on all activities in a four week period. A further strength was the measure of physical fitness using a direct measure of oxygen uptake, which is the most accurate measure of aerobic fitness. A potential weakness is in the sample size which may not have been sufficient to detect small differences as statistically significant. 


\section{Conclusion}

There were significant relationships between blood pressure, physical activity, and physical fitness, but with the exception of the relationship between habitual activity and diastolic pressure $(p=0.03)$ and past activity and systolic pressure $(\mathrm{p}=0.03)$ in men, these were not sustained after adjustment for age. When the relationships between blood pressure, physical activity, and physical fitness were examined using multiple regression to adjust for the influence of potential confounding factors, the relationship between systolic blood pressure and past activity was sustained in men, so that those who had a lifetime of participation compared with a lifetime of inactivity had a systolic blood pressure that was $6 \mathrm{mmHg}$ lower $(p<0.05)$. A reduction of $6 \mathrm{mmHg}$ in systolic blood pressure is of clinical significance and supports the hypothesis that it is the exercise habits of a lifetime, rather than more recent activity, that offer protection against hypertension. There was an inverse association between both systolic and diastolic blood pressure and physical fitness $\left(\mathrm{VO}_{2}\right.$ max) which was not sustained after adjustment for possible confounding factors. This suggests that the protective effect of activity may be independent of physical fitness level.

This study also confirms the relationship between fibrinogen and physical activity in men but the relationship was no longer significant after adjustment for possible confounders. There was, however, a relationship between fibrinogen and physical fitness in both men and women before and after adjustment for possible confounding factors. The relationship between physical activity, physical fitness and both these risk factors, blood pressure and fibrinogen, appear to have a different pattern, and the benefits of physical activity and physical fitness may act through different pathways. Longitudinal studies of physical activity and fitness may help further clarify these relationships.

We wish to thank Drs Frank Kee and John Yarnell, Department of Epidemiology and Public Health, The Queens University of Belfast, for their helpful advice and criticism.

The Northern Ireland Health and Activity was supported by The Sports Council for Northern Ireland, The Health Promotion Agency for Northern Ireland, Northern Ireland Chest, Heart and Stroke Association, The Department of Health and Social Services (NI), The Department of Education (NI), Save and Prosper, and a number of local councils.

1 Montoye HJ, Mentzer HL, Keller JB. Habitual activity and blood pressure. Med Sci Sports Exer 1972;4:175-81.

2 Gordon NF, Scott CB, Wilkinson WJ, Duncan JJ, Blair SN. Exercise and mild essential hypertension. Recommendations for adults. Sports Med 1990;10:390-404.
3 Hagberg JM. Exercise, fitness and hypertension. In: Bouchard C, Shepherd RJ, Stephens T, Sutton J, McPherson $\mathrm{B}$, eds. Exercise, fitness and health. A consensus of current knowledge. Champaign Illinois: Human Kinetics, 1988: 455-66.

4 Paffenbarger RS, Hyde RT, Wing AL, Hsieh CC. Physical activity and hypertension: An epidemiological review. Ann Med 1991;23:319-27.

5 Reaven PD, Barrett-Connor E, Edelstein S. Relationship between leisure time physical activity and blood pressure in older women. Circulation 1991;83:559-65.

6 Blair SN, Goodyear NN, Gibbons LW, Cooper KH. Physical fitness and incidence of hypertension in healthy normotensive men and women. $\mathscr{f} A M A$ 1984;252(4):487-90.

7 Stamler R, Stamler J, Gosch FC. The primary prevention of hypertension by nutritional-hygienic means: Final report of randomised clinical trial. $\mathscr{f} A M A 1989 ; 262: 1801-7$.

8 Leon AS, Connett J, Jacobs DR, Rauramaa R. Leisure time physical activity levels and the risk of coronary heart disease and death. The multiple risk factor intervention disease and death. The multiple

9 Shaper AG, Wannamethee G. Physical activity and ischaemic heart disease in middle aged British men. Br Heart 7 1991;66:384-94.

10 Kannel WB, Wolf PA, Castelli WP, D'Agostimo RB. Fibrinogen and risk of cardiovascular disease. The Framingham study. $\mathscr{f} A M A$ 1987;258:1183-6.

11 Wilhelmsen L, Svardsudd K, Korsan-Bengtson K, Larrson $\mathrm{B}$, Welin L, Tibblin G. Fibrinogen as a risk factor for stroke and myocardial infarction. $N$ Engl f Med 1984;311: 501-5

12 Morris JN, Clayton DG, Everitt MG, Semmence AM, Burgess EH. Exercise in leisure time: coronary attack and death rates. Br Heart f 1990;63:325-34.

13 Rosengren A, Wilhelmsen L, Welin T, Tsipogianni A, TegerNilsson AC, Wedel H. Social influences and cardiovascular risk factors as determinants of plasma fibrinogen concentration in a general population sample of middle aged centration in a general populat

14 Elwood PC, Yarnell JWG, Pickering J, Fehily AM, O'Brien JR. Exercise, fibrinogen, and other risk factors for ischaemic heart disease: Caerphilly prospective heart disease study. Br Heart $\mathcal{F}$ 1993;69:183-7.

15 Lee AJ, Smith WCS, Lowe GDO, Tunstall-Pedoe H. Plasma fibrinogen and coronary risk factors: The Scottish heart health study. F Clin Epidemiol 1990;9:913-9.

16 Folson AR, Wu KK, Davis CE, Conlan MG, Sorlie PD, Szklo M. Population correlates of plasma fibrinogen and factor VII, putative cardiovascular risk factors. Atherosclerosis 1991;91:191-205.

17 Ernst E. Regular exercise reduces fibrinogen levels: a review of longitudinal studies. Br $\mathcal{F}$ Sports Med 1993;27(3):175-6.

18 MacAuley D, McCrum EE, Stott G, Evans AE, Sweeney $\mathrm{K}$, Trinick TR, et al. The Northerm Ireland health and activity survey report. Belfast: HMSO, 1994.

19 .Uemura K, Pisa Z. Trends in cardiovascular disease mortality in industrial countries since 1950. World Health Stat $Q$ 1988;41:155-78

20 Kish L. Survey sampling. New York: Wiley, 1965:398-401.

21 Allied Dunbar National Fitness Survey. Activity and health research. 1992. Technical Report B. Chapter 1.

22 Clauss A. Gerinnungsphysiologische Schnellmethode zur Bestimmung des Fibrinogens. Acta Haematol 1957;17: 237.

23 European Atherosclerosis Society. Prevention of coronary heart disease-scientific background and new clinical guidelines. Nutrition, Metabolism and Cardiovascular Diseases 1992;2:113-156.

24 WHO. Arterial hypertension. Technical Report Series 628. Geneva: World Health Organisation, 1978

25 Allied Dunbar National Fitness Survey. Activity and health research. 1992

26 Connelly JB, Cooper JA, Meade TW. Strenuous exercise, plasma fibrinogen, and factor VII activity. Br Heart f 1992; 67:351-4

27 Meade TW, Mellows S, Brozovic M, et al. Haemostatic function and ischaemic heart disease: principal results of the Northwick Park Heart Study. Lancet 1986;ii:533.

28 Lakka TA, Salonen JT. Moderate to high intensity conditioning leisure time physical activity and high cardiorespiratory fitness are associated with reduced plasma fibrinogen in eastern Finnish men. F Clin Epidemiol 1993; fibrinogen in

29 Moller L, Kristensen TS. Plasma fibrinogen and ischemic heart disease risk factors. Arteriosclerosis Thromb 1991;11: 344-50. 